\title{
Commentary: Moving beyond survival: The long-term psychosocial impact of congenital heart disease
}

\author{
Alexandra Lamari-Fisher, $\mathrm{PhD},{ }^{\mathrm{a}, \mathrm{b}}$ and Carlos M. Mery, MD, $\mathrm{MPH}^{\mathrm{b}, \mathrm{c}}$
}

\footnotetext{
From the ${ }^{\mathrm{a}}$ Department of Psychiatry and ${ }^{\mathrm{c}}$ Division of Pediatric and Congenital Cardiothoracic Surgery, Department of Surgery and Perioperative Care, University of Texas Dell Medical School, Austin, Tex; and ${ }^{\mathrm{b}}$ Texas Center for Pediatric and Congenital Heart Disease, Dell Children's Medical Center, Austin, Tex.

Disclosures: Authors have nothing to disclose with regard to commercial support.

Received for publication Nov 25, 2018; accepted for publication Nov 26, 2018; available ahead of print Jan 9, 2019.

Address for reprints: Carlos M. Mery, MD, MPH, Texas Center for Pediatric and Congenital Heart Disease, University of Texas Dell Medical School, Dell Children's Medical Center, 4900 Mueller Blvd, Suite 3S.003, Austin, TX 78723-3079 (E-mail: cmery@austin.utexas.edu).

J Thorac Cardiovasc Surg 2019;157:1588-9

$0022-5223 / \$ 36.00$

Copyright (c) 2018 by The American Association for Thoracic Surgery

https://doi.org/10.1016/j.jtcvs.2018.11.086
}

What is health, and how should we measure it? These seemingly innocuous questions have significant implications for the direction of our field. Health implies more than perioperative survival or even long-term optimization of cardiac care. Health is a multifactorial and multidimensional construct that is related to the holistic well-being of an individual. "Medical" health only represents a portion of the overall well-being of an individual, with the health of the family being closely interrelated with the personal health of the individual (Figure 1). Survival for patients with congenital heart disease (CHD) has dramatically improved during the last few decades, ${ }^{1}$ so it is time for our field to focus on outcomes that go beyond measuring the traditional medical outcomes after surgery and focus instead on the long-term well-being of the patient with CHD and that patient's family.

In this issue of the Journal, Jegatheeswaran and colleagues $^{2}$ measured health-related quality of life (HRQOL) in long-term survivors after neonatal surgical treatment of interrupted aortic arch. ${ }^{2}$ This study is a welcome addition to our limited understanding of the long-term psychosocial implications of living with CHD. Jegatheeswaran and colleagues ${ }^{2}$ found HRQOL in patients was similar for most domains compared with published norms; was better for several domains related to mental health, freedom from bodily pain, and vitality; and was worse only for physical functioning among older patients. The results may indicate a tendency for patients with CHD to "learn" how to live with their disease and adapt accordingly. It is important to note in the study, however, that patients who were unable to complete the questionnaires by themselves, and obviously those who did not survive, were excluded. It is likely that these patients could have had worse HRQOL than the patients ultimately included in the study, therefore possibly biasing the results.

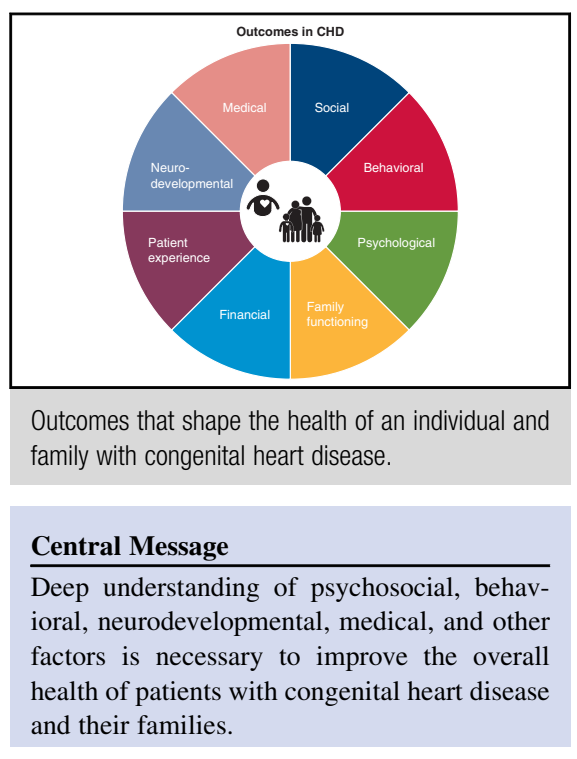

See Article page 1577.

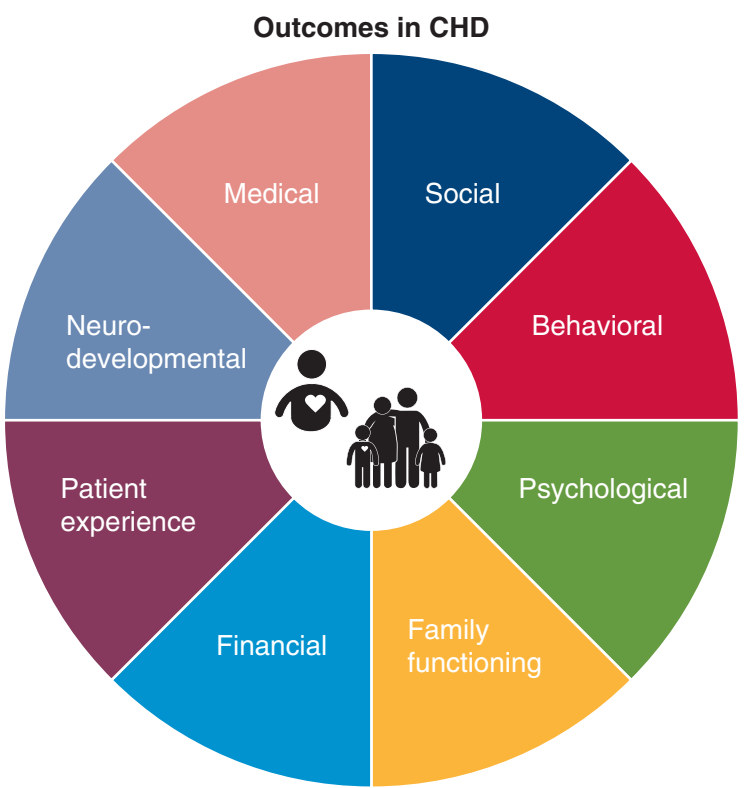

FIGURE 1. Measurable outcomes that contribute to the health of an individual with congenital heart disease and that individual's family. To gain a full understanding of overall health, it is important to account for outcomes that go beyond the traditionally measured medical outcomes. Healthrelated quality of life measures are broader than medical outcomes, but they still do not measure the entirety of the health of the individual and family. C2018 University of Texas Dell Medical School (reprinted with permission). 
An important, although not surprising, finding of the study was that mental health issues and socioeconomic factors were significantly associated with worse HRQOL. Health is the result of multiple factors, some modifiable and some not. Medical care determines only $11 \%$ of an individual's overall health outcomes. ${ }^{3}$ This means that $89 \%$ of what determines the health of an individual is a combination of individual behavior, social circumstances, environmental factors, genetics, and biology. This is quite important, because evidence suggests a bidirectional relationship between the disease process and family functioning, with CHD affecting family and caregiver functioning (eg, parenting style, stress, and maternal mental health), ${ }^{4}$ which in turn affects behavioral and neuropsychologic outcomes. ${ }^{5}$

It is imperative for our field to start focusing on studying the implications of CHD for the long-term holistic health of the patient and the patient's family (including siblings), the complex interactions between the health of the family and the health of the patient, and the identification of psychosocial risk factors and protective factors in this patient population. Only by gaining a deep understanding of all these factors will we fulfill our mission of improving the overall health of patients and families with CHD.

\section{References}

1. Benjamin EJ, Virani SS, Callaway CW, Chamberlain AM, Chang AR, Cheng S, et al. Heart disease and storke statistics-2018 update: a report from the American Heart Association. Circulation. 2018;137:e67-492.

2. Jegatheeswaran A, Jacobs ML, Caldarone CA, Kirshbom PM, Williams WG Blackstone EH, et al. Self-reported functional health status following interrupted aortic arch repair: a Congenital Heart Surgeons' Society study. J Thorac Cardiovasc Surg. 2019;157:1577-87.e10.

3. GoInvo. Determinants of Health. Available at: https://www.determinantsofhealth org. Accessed November 22, 2018.

4. Brosig CL, Mussatto KA, Kuhn EM, Tweddell JS. Psychosocial outcomes for preschool children and families after surgery for complex congenital heart disease. Pediatr Cardiol. 2007;28:255-62.

5. McCusker CG, Doherty NN, Molloy B, Casey F, Rooney N, Mulholland C et al. Determinants of neuropsychological and behavioural outcomes in early childhood survivors of congenital heart disease. Arch Dis Child. 2007;92: 137-41. 